\title{
Cultivo de Artemisia absinthium L. sob concentrações de solução nutritiva em hidroponia
}

Jose Magno Queiroz Luz ${ }^{1}$

Roberta Camargos de Oliveira²

Ariel Santivañez Aguilar ${ }^{3}$

Tatiane Nogueira Santos 4

\section{Resumo}

Losna ou absinto (Artemisa absinthium L.) é uma espécie utilizada desde a antiguidade devido a seu princípio ativo medicinal, com destaque no cenário atual por sua capacidade de fornecer substâncias úteis à indústria. Estudos sobre a produção de plantas medicinais em hidroponia podem encontrar alternativas viáveis para otimizar a produção, especialmente por fornecerem dados sobre o crescimento e produção. Neste contexto, objetivou-se avaliar o desenvolvimento do absinto sob concentrações de solução nutritiva e posição das plantas no perfil hidropônico, em sistema hidropônico NFT. O experimento foi conduzido entre os meses de abril e agosto de 2009 em delineamento de blocos ao acaso com cinco repetições, em esquema fatorial 4 × 3 . Foram avaliadas altura, massa fresca e seca da parte aérea e de raízes. As plantas tiveram seu crescimento inicial em espuma fenólica e foram irrigadas com solução nutritiva diluída a 50 \%. Após transplantadas para as bancadas de desenvolvimento, foram submetidas aos tratamentos: concentrações de solução nutritiva (50, 75, 100 e 125 \%) e posições das plantas nos perfis hidropônicos (inicial, intermediária e final). A solução nutritiva a 50 \% foi considerada a melhor opção de cultivo para absinto, uma vez que concentrações maiores não refletem em desenvolvimento significativo. Portanto, a redução pode ser utilizada sem comprometer a produção de biomassa, com economia de recursos naturais e financeiro.

Palavras-chave: Absinto. Nutrição mineral. Plantas medicinais.

\section{Introdução}

Algumas espécies de plantas sintetizam substâncias oriundas do metabolismo secundário capazes de desempenhar diversas funções, como proteção contra predadores, atratores voláteis e fornecimento de cor às plantas, facilitando a polinização, óleos aromáticos, entre outros (DEWICK, 2002).

Com o crescente interesse na exploração industrial de óleos aromáticos de espécies medicinais, investigações fitoquímicas e biológicas sobre essas espécies ganham maior atenção (RIAHI et al., 2015). Entre as espécies medicinais com potencial de destaque, encontra-se Artemisia absinthium L. da família Asteraceae, conhecida como losna ou absinto.

\footnotetext{
1 Universidade Federal de Uberlândia - UFU, Instituto de Ciências Agrárias, professor do curso de Agronomia. jmagno@umuarama.ufu.br. Av. Amazonas s/n, Bloco 2E, Campus Umuarama, CEP: 38400-902.

2 Universidade Federal de Uberlândia - UFU, Instituto de Ciências Agrárias, estudante de doutorado em Agronomia. robertacamargoss@gmail.com.

3 Universidade Federal de Uberlândia - UFU, Instituto de Ciências Agrárias, estudante de doutorado em Agronomia. ariel_trex89@hotmail.com.

4 Universidade Federal de Uberlândia - UFU, Instituto de Ciências Agrárias, engenheira agrônoma. tatianenogueirasantos@hotmail.com.
} 
A parte aérea do absinto pode ser utilizada para preparações gástricas fitoterápicas, suplementos alimentares e bebidas alcoólicas (TURAK et al., 2014). Os compostos do óleo essencial da espécie possuem variadas propriedades biológicas, incluindo antimicrobiana, acaricida, inseticida, anti-helmínticos, antisséptico e antiespasmódico (RIAHI et al., 2015).

Após descoberta a importância e vantagens dos compostos extraíveis dos vegetais, faz-se necessário o desenvolvimento de técnicas eficientes que possam produzir a matéria-prima para a extração. Portanto, meios de obtenção de produtividade e qualidade das plantas são fundamentais para sustentar o mercado e fornecer os elementos para as indústrias e população.

Prasad et al. (2012) destacam a importância em estabelecer estratégias de produção sustentáveis e economicamente viáveis para espécies capazes de fornecer moléculas bioativas. Os autores destacaram que a tecnologia de produção hidropônica é capaz de proporcionar um sistema de produção mais definido e reprodutível sob as condições de controle, em comparação com as plantas cultivadas em solos. Logo, este sistema pode resultar em melhoria da qualidade da matéria-prima para o processamento industrial e incrementar a produção e rendimento de metabólitos.

Cultivos hidropônicos referem-se a cultivos sem solo de forma mais intensiva e eficaz. As raízes das plantas são parcialmente ou completamente imersas em solução nutritiva, a qual é formada por dissolução de adubos em água de irrigação com uma concentração apropriada. A técnica apresenta expressiva expansão pelo potencial aumento de produtos agrícolas (SAVVAS et al., 2013; PUTRA; YULIANDO, 2015; LI et al., 2015).

A utilização de soluções nutritivas permite a otimização dos recursos naturais limitantes, devido à possibilidade de fornecer os nutrientes e água em proporções adequadas. A reutilização e recirculação das soluções podem evitar a contaminação das águas subterrâneas por resíduos de adubos e reduzir o custo de produção (TZERAKIS et al., 2013). Portanto, a promissora e alternativa técnica permite vantagens para o consumidor, para o produtor e para o ambiente (PAULUS et al., 2012).

A concentração da solução utilizada para suprir as necessidades das plantas merece destaque devido ao equilíbrio entre os nutrientes. Se por um lado o fornecimento abaixo do necessário impede maximizar o potencial genético das plantas, por outro, dosagens excessivas ocasionam acumulação na zona das raízes, prejudicando o crescimento das plantas e o rendimento (CARMASSI et al., 2005).

Ademais, o comprimento do perfil hidropônico também pode ser considerado um fator que interfere no desenvolvimento das plantas, em especial espécies que são responsivas e sensíveis ao fornecimento de nutrientes. Isso porque, ao longo do perfil, as plantas vão absorvendo os nutrientes diluídos e, em perfis muito longos, pode haver alteração na condutividade elétrica (LUZ et al., 2012).

A maioria dos trabalhos já realizados relata o comportamento de hortaliças folhosas, porém o interesse pelos consumidores, o aumento da demanda por outras espécies estratégicas (BIONE et al., 2014) que forneçam produtos condimentares ou medicinais salientam a necessidade do enfoque na diversificação do cultivo hidropônico.

Poucas são as informações com relação ao comportamento do absinto quanto à nutrição, especialmente em hidroponia. Logo, objetivou-se avaliar a produção desta espécie sob concentrações de solução nutritiva e posições das plantas nos perfis hidropônicos em sistema de cultivo hidropônico NFT.

\section{Material e métodos}

0 experimento conduzido em delineamento experimental foi o de blocos ao acaso (DBC) em esquema fatorial $4 \times 3$, com os fatores: concentração da solução nutritiva (I - $50 \%$, II - $75 \%$, III - 100 \%, IV - 125 \%) e posição da planta no perfil hidropônico (I - posição inicial, II - posição 
mediana e III - posição final), cada posição foi composta por cinco plantas e cada tratamento, três repetições.

A estufa hidropônica utilizada era composta por uma bancada de crescimento inicial com $4 \mathrm{~m}$ de comprimento, contendo quinze perfis de polipropileno pequenos $(50 \mathrm{~mm}$ ) com espaçamento de $10 \mathrm{~cm}$ entre perfis e $10 \mathrm{~cm}$ entre orifícios; quatro bancadas de crescimento final com $4 \mathrm{~m}$ de comprimento, cada uma com nove perfis de polipropileno médios $(100 \mathrm{~mm}$ ) para cultivo hidropônico com espaçamento de $18 \mathrm{~cm}$ entre canais e $25 \mathrm{~cm}$ entre orifícios. Os perfis, a cada três, foram abastecidos por um reservatório de plástico com capacidade de 100 litros de água, ao qual foi conectada uma bomba de pequena potência (32 Watts). Por outro lado, a bancada de crescimento inicial de mudas foi abastecida por apenas um reservatório de 100 litros. Os reservatórios foram pintados com tinta emborrachada branca com o objetivo de evitar o aquecimento da solução nutritiva. 0 sistema hidropônico adotado foi o NFT (técnica do fluxo laminar de nutrientes), com utilização da solução nutritiva proposta por Furlani et al. (1999).

A losna foi semeada em abril e colhida em agosto, conduzindo-se o experimento num total de 127 dias. A semeadura da losna foi realizada em bandejas plásticas com dimensões: 40 x 30 x $12 \mathrm{~cm}$. Foram utilizados três quilos de substrato Bioplant ${ }^{\circledR}$. O semeio foi superficial, sendo as sementes cobertas por fina camada de substrato.

Nos primeiros 22 dias, foi realizada irrigação com a solução nutritiva recomendada por Furlani et al. (1999). Após a germinação foi feito o desbaste deixando-se uma plântula por célula. As plântulas foram transferidas para espuma fenólica e posteriormente para a bancada de crescimento inicial. Nesta fase, as mudas receberam a mesma solução nutritiva, porém diluída em $75 \%$, devido ao menor desenvolvimento na fase inicial.

A circulação da solução nutritiva nos perfis foi controlada por um temporizador programado para circular de 15 em 15 minutos, das 06 h às 18 h e por 15 minutos às $24 \mathrm{~h}$.

As mudas permaneceram na bancada até os 15 dias após o transplantio. Posteriormente, as mudas foram transferidas para as bancadas de crescimento final, onde ficaram até a colheita, com irrigação com as quatro concentrações da solução nutritiva sob o mesmo regime de circulação da solução já descrito.

A solução nutritiva foi preparada a partir da água da rede urbana, a qual foi deixada em repouso (por cerca de 24 horas) para eliminação do cloro usado em seu tratamento. Para o preparo da solução nutritiva foi utilizado um kit para hidroponia fornecido pela empresa Gioplanta - Comércio e Representação Agrícola Ltda., denominado kit básico, com a quantidade de sais descritos na Tabela 1, para o preparo de 1.000 litros de solução nutritiva de concentração $100 \%$.

Tabela 1. Quantidade de sais para preparo de 1.000 litros de solução nutritiva - proposta do Instituto Agronômico

\begin{tabular}{|c|c|c|}
\hline Solução & Sal fertilizante & Quantidade (g $10 \mathrm{~L}^{-1}$ ) \\
\hline \multirow[t]{3}{*}{ A } & Nitrato de potássio & 1.200 \\
\hline & Fosfato monoamônio purificado & 200 \\
\hline & Sulfato de magnésio & 240 \\
\hline $\mathrm{B}$ & Nitrato de Cálcio especial & 600 \\
\hline \multirow[t]{5}{*}{ C } & Sulfato de cobre & 1,0 \\
\hline & Sulfato de manganês & 10,0 \\
\hline & Ácido Bórico & 5,0 \\
\hline & Molibdato de sódio & 1,0 \\
\hline & FeEDTANa $_{2}(10 \mathrm{mg} / \mathrm{ml}$ de $\mathrm{Fe})$ & $120 \mathrm{ml}$ \\
\hline
\end{tabular}

Fonte: Furlani et al. (1999). 
Os sais do kit de solução, depois de diluídos, foram adicionados ao reservatório inferior e completado o volume para 800 litros de água por meio do reservatório superior, perfazendo desta maneira 800 litros de solução com concentração de 125 \%. Esse reservatório abasteceu os reservatórios das bancadas de cultivo, onde foram feitas as diluições necessárias para cada tratamento. No momento da transferência das plantas para os perfis de $100 \mathrm{~mm}$, foram determinados o $\mathrm{pH}$ das diferentes concentrações e a condutividade elétrica.

O manejo da solução nutritiva foi realizado diariamente por meio da reposição da água consumida e do acompanhamento da condutividade elétrica (C.E.) e do $\mathrm{pH}$. A correção do $\mathrm{pH}$ foi realizada diariamente com uma solução de $\mathrm{NaOH} 1 \mathrm{M}$ ou $\mathrm{HCl}$, mantendo-o entre 5,5 e 6,5.

A solução era ajustada toda vez que a C.E. diminuía 25 \% em relação a C.E. inicial. Para o ajuste, foram utilizadas soluções específicas para tal, que foram preparadas a partir de um kit denominado kit de ajuste, também fornecido pela empresa acima citada (Tabela 2).

Tabela 2. Composição de sais das soluções de ajuste para as culturas de hortaliças de folhas

\begin{tabular}{|c|c|}
\hline Sal ou Fertilizante & Quantidade (g $1000 \mathrm{~L}^{-1}$ ) \\
\hline Nitrato de cálcio hydro Especial & 750,00 \\
\hline Nitrato de potássio & 500,00 \\
\hline Fosfato monoamônio (MAP) & 150,00 \\
\hline Sulfato de magnésio & 400,00 \\
\hline Sulfato de cobre & 0,15 \\
\hline Sulfato de zinco & 0,50 \\
\hline Sulfato de manganês & 1,50 \\
\hline Ácido bórico, ou & 1,50 \\
\hline Bórax & 2,30 \\
\hline Molibdato de sódio $\left(\mathrm{Na}_{2} \mathrm{MoO}_{4} 2 \mathrm{H}_{2} \mathrm{O}\right)$, & 0,15 \\
\hline Molibdato de amônio & 0,15 \\
\hline Tenso-Fe $®$ (FeEDDHMA-6 \% Fe.) ou & 30,0 \\
\hline Dissolvine ${ }^{\circledR}$ (FeEDTA-1 3\% Fe.) ou & 13,8 \\
\hline Ferrilene ${ }^{\circledR}$ (FeEDDHA-6 \% Fe.) ou & 30,0 \\
\hline SAL OU FERTILIZANTE & Quantidade $(\mathrm{mL})$ \\
\hline FeEDTANa $_{2}(10 \mathrm{mg} / \mathrm{ml}$ de Fe $)$ & $180 \mathrm{ml}$ \\
\hline
\end{tabular}

Fonte: Furlani et al., 1999.

Quando todas as plantas da bancada atingiram o ponto de colheita $(30-70 \mathrm{~cm})$ foram avaliadas as seguintes características: altura de planta, massa de matéria fresca de parte aérea e de raiz. A totalidade da parte aérea e das raízes de cada parcela foi submetida à secagem em estufa com circulação de ar forçada a $65^{\circ} \mathrm{C}$ até que atingiram massa constante, para obtenção da massa de matéria seca da parte aérea e raiz.

Foram realizadas amostragem de folhas para quantificação de nutrientes. As amostras após secagem foram moídas e determinados os teores foliares dos macronutrientes: nitrogênio, fósforo, potássio, cálcio, magnésio, enxofre e micronutrientes: boro, cobre, ferro, manganês e zinco (EMPRESA BRASILEIRA DE PESQUISA AGROPECUÁRIA - EMBRAPA, 2013).

Os resultados obtidos foram submetidos à análise de variância. A comparação de médias foi feita por meio do teste de Tukey a $5 \%$ de probabilidade. Fatores quantitativos foram avaliados por meio de teste de médias devido à ausência de ajuste aos modelos matemáticos, evidenciados por meio de baixos coeficientes de determinação ou não significância dos modelos. 


\section{Resultados e discussão}

Não houve interação entre as concentrações de solução nutritiva e posição no perfil hidropônico, portanto os fatores foram avaliados de forma isolada.

A concentração de nutrientes nas folhas de absinto, tanto macros quanto micronutrientes, apresentou acúmulos diferenciados conforme a quantidade de nutrientes fornecidos. Tal resultado era esperado, uma vez que a diferença de concentração interfere na dinâmica de absorção, oriunda da competição entre os nutrientes pelos sítios de absorção. Maiores teores de P, K, Cu, Zn, Mn foram observados na concentração de solução nutritiva proposta por Furlani et al. (1999) a 50 \%; Ca e Fe foram mais pronunciados na concentração de $75 \%$, enquanto N, Mg, S e B na concentração de 125 \% (Figuras 1 e 2).

Figura 1. Concentração de macronutrientes (N, P, K, Ca, Mg e S) nas folhas de Artemisia absinthium L. sob a concentração de solução nutritiva proposta por Furlani et al. (1999).

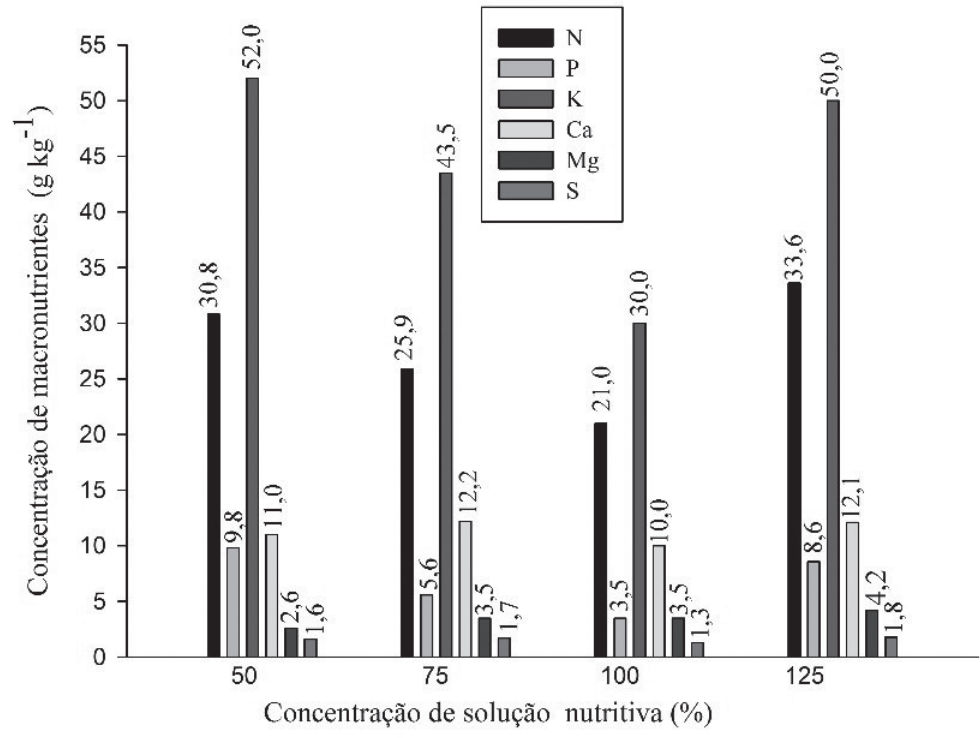

Fonte: Elaborada pelos autores (2017).

Figura 2. Concentração de micronutrientes (B, Cu, Fe, Mn e Zn) nas folhas de Artemisia absinthium L. sob a concentração de solução nutritiva proposta por Furlani et al. (1999)

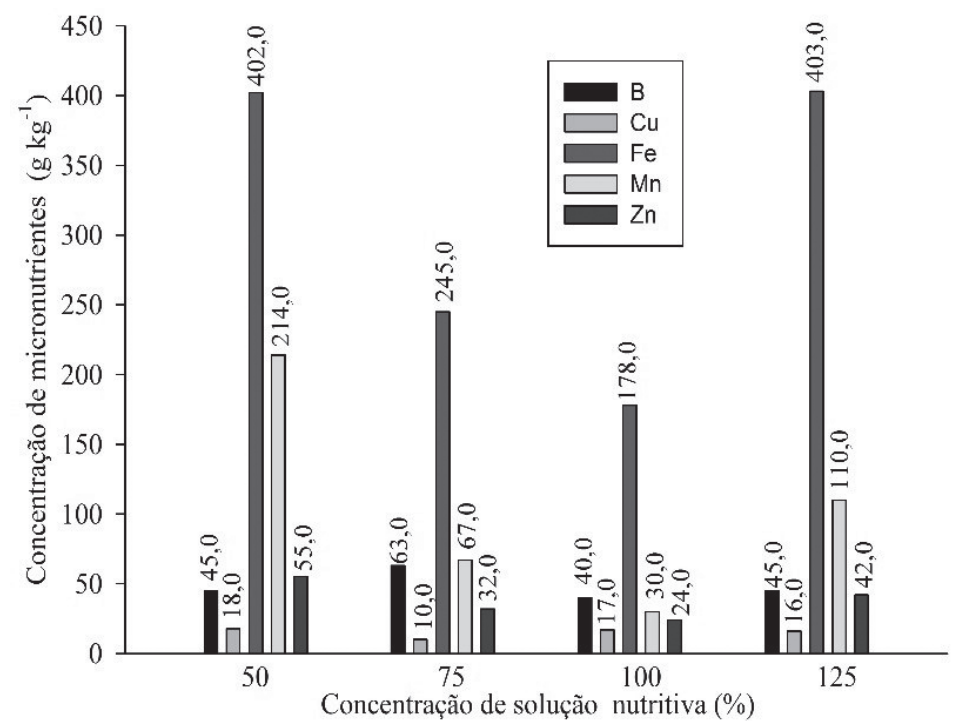

Fonte: Elaborada pelos autores (2017). 
É fundamental observar as quantidades de nutrientes que as plantas conseguem absorver para se evitar desequilíbrios de nutrientes e consequente reduções no desenvolvimento vegetal. Neocleous e Savvas (2015), em estudo do efeito de proporções de macronutrientes em solução nutritiva de circulação na absorção do melão, observaram que o aumento na concentração de íons para manter um padrão $\mathrm{K}^{+}$: $\mathrm{Ca}^{2+}$ : $\mathrm{Mg}^{2+}$ ocasionou desbalanços prejudiciais, o que restringiu o rendimento de frutas frescas em $20 \%$ devido aos efeitos osmóticos. Os autores mencionaram ainda a interferência nos fatores osmóticos, sendo que a absorção de nutrientes pode não passar por inibição devido à salinidade elevada na solução reciclada ou não responder a pequenas diferenças na concentração de nutrientes nos tecidos vegetais.

Souza et al. (2005), em um trabalho com níveis de condutividade elétrica no cultivo de berinjela, verificaram que o aumento da condutividade elétrica se relacionou ao aumento do íon potássio e redução para o magnésio. Essa relação entre os nutrientes pode ser observada neste trabalho, sendo que a concentração de 50 \% refletiu em maior concentração de $\mathrm{K}$ e menor teor de $\mathrm{Mg}$. Entretanto, concentrações maiores de sais na solução alteraram a dinâmica de absorção ocasionando redução no teor de $\mathrm{K}$ e aumento do $\mathrm{Mg}$.

A disponibilidade de cátions e ânions no solo ou solução nutritiva determinam a sua absorção pelas plantas (OLIVEIRA et al., 2001). Cátions como K e Mg competem pelo mesmo sítio de absorção e alterações na concentração desses e refletem em sua absorção e translocação, sendo que a presença excessiva de um pode prejudicar os processos de absorção de outros (ORLANDO FILHO et al., 1996).

É bom lembrar que os nutrientes se correlacionam e estão inseridos em uma dinâmica de absorção, as quais ocorrem de acordo com a quantidade de cada nutriente presente na solução disponível ao sistema radicular. Em trabalho com algodão, por exemplo, Araújo e Silva (2012) observaram que o fornecimento de boro afetou positivamente o teor de nitrogênio e reduziu a eficiência de absorção e o transporte de fósforo.

Espécies com grande variabilidade quanto às características de interesse agronômico apresentam escassas informações quanto ao estado nutricional e o crescimento quando submetidas a concentrações de nutrientes (VASCONCELOS et al., 2014). Isto salienta a necessidade de mais esforços para o entendimento quanto ao comportamento de espécies com nobre valor medicinal como o absinto.

$O$ teste $F$ não foi significativo para os fatores concentrações de solução nutritiva e posição do perfil hidropônico quanto à altura, a qual variou de 42,59 a 46,7 entre as doses e de 43,45 a 44,16 entre as posições no perfil (Figura 3).

Figura 3. Médias da altura das plantas de Artemisia absinthium L. sob concentrações de solução nutritiva proposta por Furlani et al. (1999) e posições no perfil hidropônico
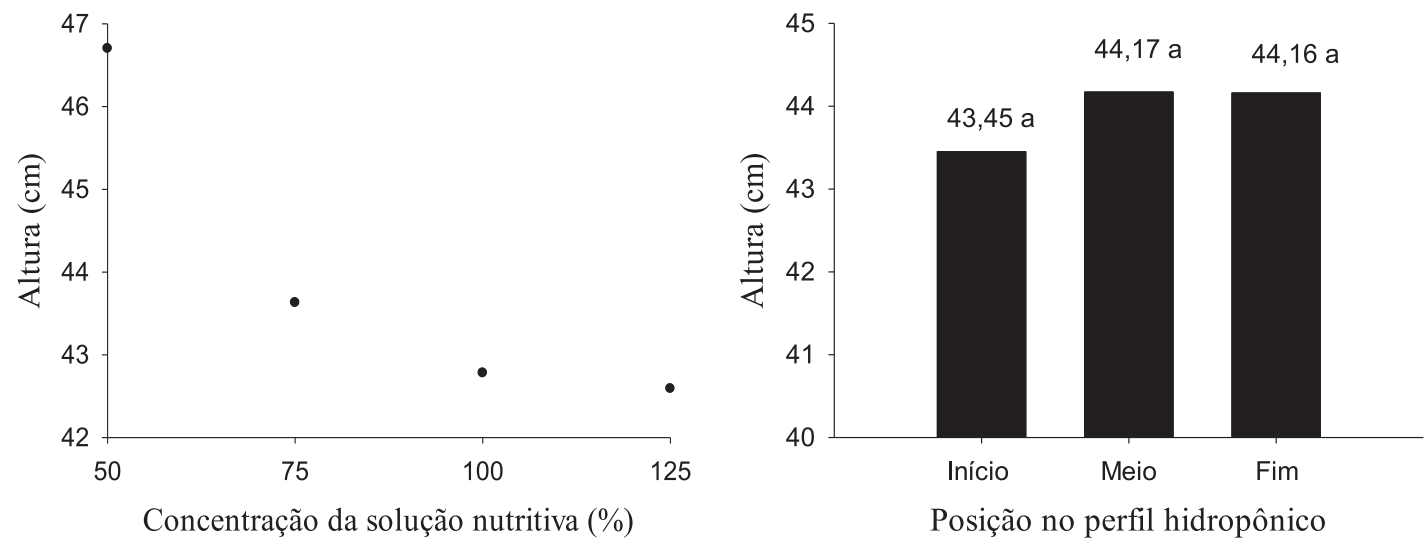

Fonte: Elaborada pelos autores (2017). 
A concentração de íons (força iônica) da solução nutritiva e a obtenção da formulação adequada, que garanta o desenvolvimento máximo sem excedentes e faltas, são complexas devido à dinâmica entre os nutrientes. Há constantes buscas por respostas na produtividade visando reduzir a concentração das soluções nutritivas e a concentração de nitrato nos tecidos vegetais, com consequente redução nos custos de produção por meio do aumento da eficiência do uso dos nutrientes (ARAÚJO et al., 2013).

$O$ teste $F$ não foi significativo entre as concentrações de solução nutritiva para massas de matéria secas de parte aérea (MSPA) e raiz (MSR), portanto, as massas secas de parte aérea e raiz não foram influenciadas pelas concentrações de solução nutritiva. A MSPA e MSR variou entre 80,55 e 105,55 e 46,66 e 63,88 g planta $^{-1}$, respectivamente (Figura 4).

Figura 4. Médias de massa seca da parte aérea e massa seca da raiz das plantas de Artemisia absinthium L. sob concentrações de solução nutritiva proposta por Furlani et al. (1999).

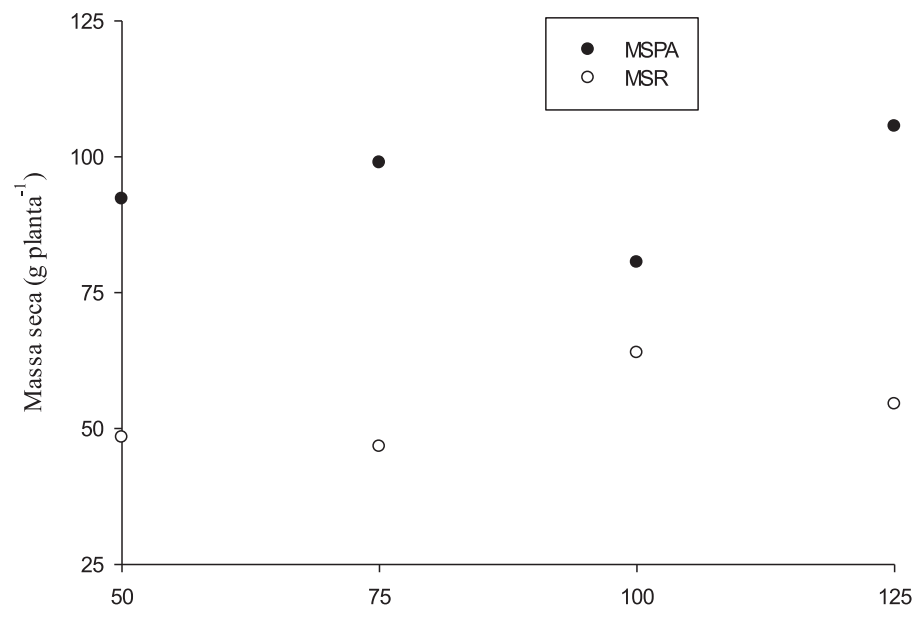

Fonte: Elaborada pelos autores (2017).

Porém, quando observada a posição das plantas no perfil hidropônico, aquelas cultivadas no fim tiveram maior massa seca de raiz (Figura 5).

Figura 5. Médias de massa seca da parte aérea e massa seca da raiz das plantas de Artemisia absinthium L. de acordo com as posições no perfil hidropônico

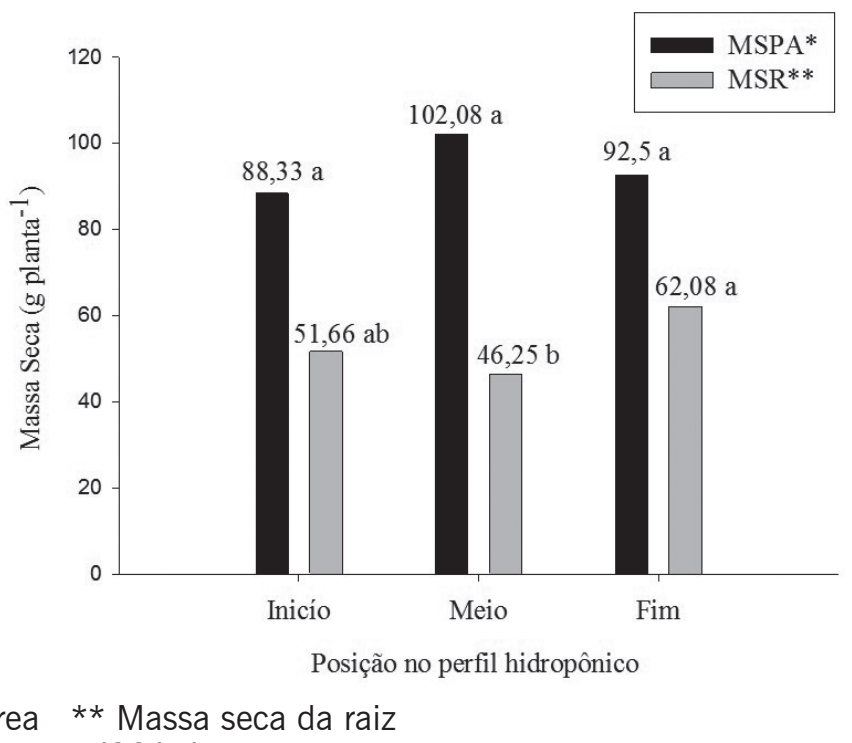

*Massa seca da parte aérea ** Massa seca da raiz

Fonte: Elaborada pelos autores (2017). 
As reduções da concentração da solução nutritiva também proporcionaram os mesmos valores de taxa de crescimento comparado a 100 \% em trabalhos realizados por Cometti et al. (2008) em cultivo de alface em sistema NFT e Araújo et al. (2013) em cultivo de tomate cereja. Os autores reforçaram que a redução na concentração da solução nutritiva permite economia no custo da solução nutritiva básica, sem comprometer a produtividade.

Luz et al. (2011) também verificaram respostas favoráveis ao crescimento de rúcula (Eruca sativa), sob cultivo com menor concentração da solução nutritiva de Furlani et al. (1999) (50 \%).

Luz et al. (2012) em estudo com coentro e salsa observaram resultado oposto ao presente estudo, com maiores massas secas nas posições inicial e intermediária dos perfis hidropônicos, com reflexos em maiores rendimentos nas duas espécies estudadas.

\section{Conclusão}

A solução nutritiva a 50 \% mostra-se a melhor opção de cultivo para absinto, uma vez que concentrações maiores não refletem em desenvolvimento significativo. Portanto, a redução pode ser utilizada sem comprometer a produção de biomassa, com economia de recursos naturais e financeiro.

\section{Cultivation of Artemisia absinthium under nutrient solution concentrations in hydroponics}

Wormwood (Artemisa absinthium L.) is a species used since ancient times due to its medicinal active principles, standing out in the current scenario for its ability to provide useful substances to industry. Studies on the production of medicinal plants in hydroponics can provide viable alternative to optimize production, especially for generating growth and production data. In this context, the objective was to evaluate the development of wormwood under nutrient solution concentrations and position of plants in hydroponic profile, in a hydroponic system NFT. The experiment was conducted between April and August, 2009, in a randomized block design with five replications, in a 4 x 3 factorial scheme. Height, fresh and dry weight of shoots and roots were assessed. The plants had their initial growth of phenolic foam and were irrigated with nutrient solution diluted to $50 \%$. After transplanting them to the development profiles, they were submitted to the treatments: nutrient solution concentrations (50, 75, 100 and $125 \%$ ) and positions of plants in the profile (initial, intermediate and final). The nutrient solution at $50 \%$ was considered the best option for wormwood cultivation, since higher concentrations do not reflect significant development. Therefore, the reduction in concentration may be used without decreasing production, saving natural and financial resources.

Keywords: Medicinal plants. Plant nutrition. Wormwood.

\section{Agradecimentos}

À FAPEMIG e à CAPES pelo auxílio financeiro. 


\section{Referências}

ARAÚJO, L.; SILVA, K. J. P.; LEMOS, L. M. C.; MILAGRES, C. C.; CARDOSO, D. S. C. P.; ALVES, L. C.; PEREIRA, P. R. G. Tomate cereja cultivado em diferentes concentrações de solução nutritiva no sistema hidropônico capilar. Revista Unimontes Científica, v. 15, n. 1, p. 18-27, 2013. Disponível em: <http://www.ruc.unimontes.br/index.php/unicientifica/article/view/131 > . Acesso em: 20 dez. 2017.

ARAÚJO, E. O.; SILVA, M. A. C. Efeito de doses de boro e zinco na absorção de nitrogênio e fósforo pelo algodoeiro em cultivo hidropônico. Revista Brasileira de Ciências Agrárias, v. 7, n. 4, p. 574-579, 2012. Disponível em: <http://dx.doi.org/ 10.5039/agraria.v7i4a1731 >. Acesso em: 13 dez. 2017.

BIONE, M. A. A.; PAZ, V. P. S.; SILVA, F.; RIBAS, R. F.; SOARES, T. M. Crescimento e produção de manjericão em sistema hidropônico NFT sob salinidade. Revista Brasileira de Engenharia Agrícola e Ambiental, v. 18, n. 12, p. 1228-1234, 2014. Disponível em: <http://dx.doi.org/10.1590/18071929/agriambi.v18n12p1228-1234>. Acesso em: 13 dez. 2017.

CARMASSI, G.; INCROCCI, L.; MAGGINI, R.; MALORGIO, F.; TOGNONI, F.; PARDOSSI, A. Modeling salinity build-up in recirculating nutrient solution culture. Journal of Plant Nutrition, v. 28 n. 3 p. $431-$ 445, 2005. Disponível em: <http://dx.doi: 10.1081/PLN-200049163>. Acesso em: 13 dez. 2017.

COMETTI, N. N.; MATIAS, G. C. S.; ZONTA, E.; MARY, W.; FERNANDES, M. S. Efeito da concentração da solução nutritiva no crescimento da alface em cultivo hidropônico sistema NFT. Horticultura Brasileira, v. 26, n. 2, p. 252-257, 2008. Disponível em: <http://doi.org/10.1590/S010205362008000200027 >. Acesso em: 14 dez. 2017.

DEWICK, P. M. Medicinal Natural Products: a Biosynthetic Approach. West Sussex: John Wiley \& Sons, 2002, p. 7-38.

EMBRAPA (EMPRESA BRASILEIRA DE PESQUISA AGROPECUÁRIA). Sistema Brasileiro de Classificação de Solos. 3. ed. Brasilia, (DF): Embrapa, 2013, p. 95-133.

FURLANI, P. R.; SILVEIRA, L. C. P.; BOLONHEZI, D.; FAQUIN, V. Cultivo hidropônico de plantas. Campinas: Instituto Agronômico, 1999, p. 11-12. Boletim Técnico, 180.

LI, C.; DONG, Y.; LEI, Y.; WU, D.; XU, P. Removal of low concentration nutrients in hydroponic wetlands integrated with zeolite and calcium silicate hydrate functional substrates. Ecological Engineering, v. 82, n. 1, p. 442-450, 2015. Disponível em: <http://doi:10.1016/j.ecoleng.2015.05.003>. Acesso em: 20 dez. 2017.

LUZ, J. M. Q.; COSTA, C. C.; GUERRA, G. M. P.; SILVA, M. A. D.; HABER, L. L. Efeito da variação da solução nutritiva no cultivo hidropônico de rúcula. Revista Verde de Agroecologia e Desenvolvimento Sustentável, v. 6, n. 3, p. 76-82, 2011. Disponível em: http://www.gvaa.com.br/revista/index.php/ RVADS/article/view/716/651. Acesso em: 20 dez. 2017.

LUZ, J. M. Q.; ANDRADE, L. V.; DIAS, F. F.; SILVA, M. A. D.; HABER, L. L.; OLIVEIRA, R. C. Produção hidropônica de coentro e salsa crespa sob concentrações de solução nutritiva e posições das plantas nos perfis hidropônicos. Bioscience Journal, v. 28, n. 1, p. 589-597, 2012. Disponível em: <http:// ccarevista.ufc.br/seer/index.php/ccarevista/article/view/257/252 >. Acesso em: 20 dez. 2017. 
NEOCLEOUS, D.; SAVVAS, D. Effect of different macronutrient cation ratios on macronutrient and water uptake by melon (Cucumis melo) grown in recirculating nutrient solution. Journal of Plant Nutrition and Soil Science, v. 178, n. 2, p. 320-332, 2015. Disponível em: < http://dx.doi.org/10.1002/ jpln.201400288>. Acesso em: 20 dez. 2017.

OLIVEIRA, F. A.; CARMELLO, Q. A. C.; MASCARENHAS, H. A. A. Disponibilidade de potássio e suas relações com cálcio e magnésio em soja cultivada em casa-de-vegetação. Scientia Agricola, v. 58, n. 2, p. 329-335, abr./jun. 2001. Disponível em: http://www.scielo.br/pdf/sa/v58n2/4424.pdf. Acesso em: 20 dez. 2017.

ORLANDO FILHO, J. O.; BITTENCOURT, V. C.; CARMELLO, Q. A. C.; BEAUCLAIR, E. G. F. Relações $\mathrm{K}$, Ca e Mg de solo areia quartzosa e produtividade da cana-de-açúcar. Revista STAB, Piracicaba, v. 14, n. 5, p. 13-17, 1996.

PAULUS, D.; PAULUS, E.; NAVA, G. A.; MOURA, C. A. Crescimento, consumo hídrico e composição mineral de alface cultivada em hidroponia com águas salinas. Revista Ceres, v. 59, n. 1, p. 110-117, 2012. Disponível em: <http://doi.org/10.1590/S0034737X2012000100016>. Acesso em: 20 dez. 2017.

PRASAD, A.; PRAGADHEESH, V. S.; MATHUR, A.; STRIVASTAVA, N. K.; SINGH, M.; MATHUR, A. K. Growth and centelloside production in hydroponically established medicinal plant-Centella asiatica (L.). Industrial Crops and Products, v. 35, n. 1, p. 309-312, 2012. Disponível em: <http://dx.doi. org/10.1016/j.indcrop.2011.06.020 >. Acesso em: 15 fev. 2018.

PUTRA, P. A.; YULIANDO, H. Soilless culture system to support water use efficiency and product quality: A review. Agriculture and Agricultural Science Procedia, v. 3, n. 1, p. 283-288, 2015. Disponível em: <http://doi.org/10.1016/j.aaspro.2015.01.054>. Acesso em: 15 fev. 2018.

RIAHI, L.; GHAZGHAZI, H.; AYARI, B.; AOUADHI, C.; KLAY, I.; CHOGRANI, H.; CHERIF, A.; ZOGHLA$\mathrm{MI}, \mathrm{N}$. Effect of environmental conditions on chemical polymorphism and biological activities among Artemisia absinthium L. essential oil provenances grown in Tunisia. Industrial Crops and Products, v. 66, n. 1, p. 96-102, 2015. Disponível em: <http://doi.org/10.1016/j.indcrop.2014.12.036>. Acesso em: 15 fev. 2018.

SAVVAS, D.; GIANQUINTO, G.; TUZEL, Y.; GRUDA, N. Soilless culture. Roma: Editora FAO, 2013, p. 303-306.

SOUZA, V. S.; SOARES, I.; CRISÓSTOMO, L. A.; SILVA, L. A.; HERNANDEZ, F. F. F. Influência da condutividade elétrica da solução nutritiva na acumulação de matéria seca e teores de nutrientes em berinjela cultivada em pó de coco. Revista Ciência Agronômica, v. 36, n. 2, p. 123-128, 2005. Disponível em: http://ccarevista.ufc.br/seer/index.php/ccarevista/article/view/257. Acesso em: 20 nov. 2017.

TURAK, A.; SHI, S. P.; JIANG, Y.; TU, P. F. Dimeric guaianolides from Artemisia absinthium. Phytochemistry, v. 105, p. 109-114, Sep. 2014. Disponível em: <http://dx.doi.org/10.1016/j.phytochem.2014.06.016>. Acesso em: 10 dez. 2017. 
TZERAKIS, C.; SAVVAS, D.; SIGRIMIS, N.; MAVROGLANNOPOULUS, G. Uptake of Mn and Zn by cucumber grown in closed hydroponic systems as influenced by the $\mathrm{Mn}$ and $\mathrm{Zn}$ concentrations in the supplied nutrient solution. Hortscience, v. 48, n. 3, p. 373-379, 2013. Disponível em: <http:// hortsci.ashspublications.org/content/48/3/373.full>. Acesso em: 15 fev. 2018.

VASCONCELOS, L. S. B.; NETO, E. G.; NASCIMENTO, C. W. A.; BARRETO, L. P. Desenvolvimento de plantas de coentro em função da força iônica da solução nutritiva. Pesquisa Agropecuária Pernambucana, v. 19, n. 1, p. 11-19, 2014. Disponível em:<http://dx.doi.org/10.12661/pap.2014.003>. Acesso em: 17 dez. 2017.

\section{Histórico editorial:}

Submetido em: 29/08/2016

Aceito em: 03/04/2017

Como citar:

\section{$\underline{\mathrm{ABNT}}$}

LUZ, J. M. Q.; OLIVEIRA, R. C. de; AGUILAR, A. S.; SANTOS, T. N. Cultivo de Artemisia absinthium L. sob concentrações de solução nutritiva em hidroponia. Revista Agrogeoambiental, Pouso Alegre, v. 10, n. 1, p. 117-128, jan./mar. Doi: http://dx.doi.org/10.18406/2316-1817v10n220181082

APA

LUZ, J. M. Q., OLIVEIRA, R. C. de, AGUILAR, A. S. \& SANTOS, T. N. (2018). Cultivo de Artemisia absinthium L. sob concentrações de solução nutritiva em hidroponia. Revista Agrogeoambiental, 10 (1), 117-128.

Doi: http://dx.doi.org/10.18406/2316-1817v10n220181082

$\underline{\text { ISO }}$

LUZ, J. M. Q.; OLIVEIRA, R. C. de; AGUILAR, A. S. e SANTOS, T. N. Cultivo de Artemisia absinthium L. sob concentrações de solução nutritiva em hidroponia. Revista Agrogeoambiental, 2018, vol. 10, n. 1, pp. 117128. Eissn 2316-1817. Doi: http://dx.doi.org/10.18406/2316-1817v10n220181082

VANCOUVER

Luz JMQ, Oliveira RC de, Aguilar AS, Santos TN. Cultivo de Artemisia absinthium L. sob concentrações de solução nutritiva em hidroponia. Rev agrogeoambiental. 2018 jan/mar; 10(1): 117-128.

Doi: http://dx.doi.org/10.18406/2316-1817v10n220181082 